\title{
American cutaneous leishmaniasis cases in the metropolitan region of Manaus, Brazil: association with climate variables over time
}

\author{
Rodrigo Augusto Ferreira de Souza, ${ }^{1}$ Rita Valéria Andreoli, ${ }^{1}$ Mary Toshie Kayano, ${ }^{2}$ \\ Afrânio Lima Carvalho ${ }^{3}$ \\ ${ }^{1}$ Universidade do Estado do Amazonas, Escola Superior de Tecnologia, Manaus, AM; \\ 2 Instituto Nacional de Pesquisas Espaciais, São José dos Campos, SP; \\ ${ }^{3}$ Programa de Pós-Graduação em Clima e Ambiente, Instituto Nacional de Pesquisas da \\ Amazonia-Universidade do Estado do Amazonas, Manaus, AM, Brazil
}

\begin{abstract}
A temporal series of the normalized difference vegetation index (NDVI) and other environmental parameters covering the years 20022009 was used for the study of the potential association between the climate and the number of cases of American cutaneous leishmaniasis (CL) in Manaus Metropolitan Region (MMR), State of Amazonas, Brazil. The results show that CL has a marked seasonality and a strong linkage with local climate conditions. Dry and warm conditions favor the vector, while the maximum number of CL cases occurs during the following wet season. This has a clear relation to the El Niño/La Niña Southern Oscillation (ENSO) and the results presented here show that uncharacteristic dry conditions in the MMR follow El Niño after a lag
\end{abstract}

Correspondence: Rodrigo Augusto Ferreira de Souza, Universidade do Estado do Amazonas, Escola Superior de Tecnologia, Av. Darcy Vargas 1200, Parque 10 de Novembro, 69065-020 Manaus, AM, Brazil.

Tel: +55.92.3214.4323. E-mail: souzaraf@gmail.com

Key words: American cutaneous leishmaniasis; Climate association; ENSO; Remote sensing; NDVI.

Funding: the authors thank the Fundação Nacional de Saúde for providing the data of cutaneous leishmaniasis cases in the Manaus metropolitan region, the Financiadora de Estudos e Projetos of Brazil (FINEP/REMCLAMUEA) and the Fundação de Amparo à Pesquisa do Estado do Amazonas (FAPEAM/PROESTADO) for research support and grant scholarship. The second and third authors were partially supported by the Conselho Nacional de Desenvolvimento Científico e Tecnológico of Brazil (CNPq).

Acknowledgements: the authors thank Dr. Grinsted for provinding the software for the wavelet coherence and phase calculations.

Received for publication: 12 January 2015.

Revision received: 19 March 2015.

Accepted for publication: 1 April 2015.

@C Copyright R.A.Ferreira de Souza et al., 2015

Licensee PAGEPress, Italy

Geospatial Health 2015; 10:314

doi:10.4081/gh.2015.314

This article is distributed under the terms of the Creative Commons Attribution Noncommercial License (by-nc 3.0) which permits any noncommercial use, distribution, and reproduction in any medium, provided the original author(s) and source are credited. period of 3 months, while wet conditions follow La Niña, again after a lag period of 3 months. El Niño brings dry conditions with warming of the land surface leading to increased growth of trees and bushes as indicated by rising NDVI values, eventually producing increased numbers of CL cases, with a peak of new cases occurring 4 to 5 months later. La Niña, on the other hand, produces wet and cool weather, which is less favorable for the leishmaniasis vector and therefore results in comparatively lower number of CL cases. Since these seasonal climate changes affect the dynamics of the CL vector, and thus the number of CL cases, a close watch of the ENSO phenomenon and the weather type it brings should be useful for monitoring and control of CL in the MMR.

\section{Introduction}

Leishmaniasis presents as cutaneous, muco-cutaneous or visceral inflammation. The dominant infectious species in South America include members of the Leishmania and the Viannia subgenus. American cutaneous leishmaniasis (CL) can cause skin deformations with psychological and socio-economic implications and deserves therefore the attention of policy makers. The World Health Organization (WHO) recognizes leishmaniasis as an important, protozoan, parasitic disease with a significant public health problem in various parts of the tropical world, including northern South America (2013; http://www.who.int/leishmaniasis/en/). It is a neglected tropical disease with an estimated 12 million cases globally and with an annual addition of 1.5-2 million new cases, 1-1.5 million of which are cutaneous and 0.5 million visceral. In the Americas, the disease is transmitted, in general, by the bite of the infected female Lutzomyia sand fly. Cutaneous leishmaniasis is broadly spread over Brazil with cases registered in all regions. During the 1960 s, the disease was limited to rural areas, but from the 1970s onwards, this disease started to be detected in suburban-urban areas (Passos et al., 1984) as well. This disagrees with the idea that CL would become less important as cities developed eliminating vector habitats and natural outbreaks (Pessoa and Barreto, 1948). Out of the 610,256 CL cases registered in Brazil from 1980 to 2005, 37\% were in northern Brazil with $22.4 \%$ in the State of Amazonas (Barbosa et al., 2008). During the last few years, the number of CL cases in the State of Amazonas increased significantly, mainly due to the agricultural use of areas previously occupied by dense tropical forest (Guerra et al., 1998; Barbosa et al., 2008). The Brazilian epidemiological information service Sistema de Informação de Vigilância Epidemiológica (SIVEP) states that the Manaus, Rio Preto da Eva, Presidente Figueiredo and Itacoatiara were the cities in 
Amazonas with the largest number of CL cases during the 1992-2009 period. There were also cases of the disease in other cities of Amazonas as well as in the urban and rural areas around neighboring communities belonging to the Manaus Metropolitan Region (MMR).

Environmental variables, such as rainfall, temperature and humidity, among others, influence the life-cycle of the Lutzomyia sand fly, and therefore eventually also the number of CL cases. In the tropics, the El Niño/La Niña Southern Oscillation (ENSO) strongly modulates the inter-annual changes of the prevailing environmental variables. The ENSO phenomenon represents a coupled oceanic-atmospheric undulation with a period varying from 2 to 7 years that includes warm (the El Niño episode) and cold extremes (the La Niña episode) in addition to neutral conditions. The former features an above-normal sea level pressure (SLP) in the western tropical Pacific, below-normal SLP in the south-eastern tropical Pacific, positive sea surface temperatures (SST) and weakened trade winds in the central and eastern equatorial Pacific (e.g., Philander, 1990), while the latter is characterized by a reversed pattern with respect to SST, SLP and winds in the tropical Pacific (Kousky and Ropelewski, 1989).

The vectors of malaria and dengue are susceptible to meteorological changes as they affect the life-cycles of their insect vectors (Patz et al., 2000; Gagnon et al., 2002; Delgado et al., 2004). However, the few studies concerning leishmaniasis show conflicting results, in particular in the Americas. Cabaniel et al. (2005) analyzed the ENSO effect on the incidence of leishmaniasis in the state of Sucre, Venezuela during the 1994-2003 period finding a high number of CL cases during La Niña (wet conditions) and low numbers during El Niño events (dry conditions) in that region. Cardenas et al. (2006), on the other hand, found an increased number of leishmaniasis cases during El Niño and a reduced number during La Niña events in north-eastern Colombia during the 1985-2002 period. Because the two regions studied were influenced by the same ENSO effects, and the periods analyzed overlapped to a large extent, the inconsistent results were not expected. However, both studies highlighted the important role of climate variability for the CL incidence. Therefore, other areas of the Amazon region might be of interest in the context of inter-annual climate variability and CL incidence as, it could potentially clarify the above mentioned inconsistency.

El Niño/La Niña Southern Oscillation is an important factor in the context of the epidemiological variability and plays a significant role on the inter-annual climate variability patterns in many parts of the globe (Ropelewski and Halpert, 1987). Furthermore, Chaves and Pascual (2006), studying the relations between the incidence of CL in Costa Rica and the climate cycles, suggest that the 3 -year period cycle in the incidence of this disease is due to ENSO. In the Amazon region, the ENSO-related climate variability affects the flora and fauna due to lack of rainfall during El Niño and excess rain during La Niña events (Marengo, 1992). Analysis of a time series of disease incidence constitutes an important approach to understand the dynamics. The classical methods of time series analysis presume that it is stationary, i.e. the statistical properties of the time series are invariant with respect to time. However, this assumption is not valid for epidemiological time series, for which wavelet analysis as described by Cazelles et al. (2007) appears to be an attractive tool.

Large-scale, conventional observations of environmental parameters, such as land surface temperature (LST) and precipitation, are scarce, particularly with regard to relatively long periods of time. However, they are becoming more common thanks to satellite-generated, remotely sensed data. For example, the normalized difference vegetation index (NDVI) that indicates 'greening' of the land cover has become an important measure in the analyses of epidemic diseases (Werneck and Maguire, 2002; Green and Hay, 2002; Cardenas et al.,
2006; Tourre et al., 2008; Bounoua et al., 2013). Besides the usual application of the NDVI to assess the vegetation coverage in a given area, these studies have shown that the NDVI time series, as well as precipitation and humidity time series, are strongly correlated to disease occurrences. Variations in these parameters affect the life-cycles of the vectors of many tropical diseases, including CL. In this context, Bavia et al. (2005) related the low NDVI values to the high number of sand flies and to the presence of human and canine visceral leishmaniasis in north-western Bahia State, Brazil. Since the MMR has a considerably higher number of CL cases than many other parts of Brazil, the present paper aims to further examine the relation between the number of these cases and the temporal variations of the local parameters including the ENSO effects.

\section{Materials and Methods}

\section{Study area}

Eight Brazilian cities within the greater Manaus area (MMR) in the Amazonas State, i.e. Manaus, Careiro da Várzea, Iranduba, Itacoatiara, Manacapuru, Novo Airão, Presidente Figueiredo and Rio Preto da Eva, were investigated with reference to the number of CL cases in the 2002-2009 period. The MMR for the gridded variables refers to the area border by latitudes $0.75^{\circ} \mathrm{N}$ to $4.75^{\circ} \mathrm{S}$ and longitudes $64.25^{\circ} \mathrm{W}$ to $57.75^{\circ} \mathrm{W}$

\section{Cutaneous leishmaniasis data}

The SIVEP provided the monthly time series of the number of CL cases for the eight cities.

\section{Climate variables}

All variables related to the MMR and used here were collected on a monthly basis for the 2002-2009 period. Land surface temperature and NDVI data were obtained from the moderate-resolution imaging spectro-radiometer instrument (http://terra.nasa.gov/About/MODIS/ about_modis.html) operating on the Terra spacecraft. These are gridded data with a spatial resolution of $5 \mathrm{~km}^{2}$ available at from the National Aeronautics and Space Administration (NASA) website (http://modis-land.gsfc.nasa.gov/).

Monthly gridded precipitation (PRP) time series over the MMR area were obtained from the gauge-based $0.5^{\circ}$-resolution reconstructions of the Global Precipitation Climatology Center (GPCC) (Becker et al., 2005; Rudolf and Rubel, 2005). The GPCC v.6 full data reanalysis version was used (Schneider et al., 2013).

We used the local, averaged monthly values of the environmental indices NDVI, LST and PRP covering the 2002-2009 period, looking for potential associations between these values and the seasonal distribution of CL cases in the MMR area. The relationships were analyzed through monthly boxplots (Wilks, 2006).

\section{El Niño/La Niña Southern oscillation data}

The equatorial Pacific area limited by latitudes $5^{\circ} \mathrm{N}$ to $5^{\circ} \mathrm{S}$ and $170^{\circ} \mathrm{W}$ to $120^{\circ} \mathrm{W}$, a region in the central Pacific, is referred to as El Niño 3.4. The monthly SST index for this area was used to represent the ENSO variations under study (obtained at http://www.cpc. noaa.gov/data/indices/sstoi.indices) for the $2002-2009$ period. This El Niño 3.4 index was utilized to identify the occurrence of El Niño and La Niña events. 


\section{Approach}

The relation between two SST time series was examined by measuring the phase differences between them, which express the degree of wavelet coherence. The calculation procedures described by Torrence and Webster (1999) and Grinsted et al. (2004) were used. Briefly, the phase relations between two time series (A and B) are indicated by arrows with the in-phase relation characterized by the arrow pointing right $\left(0^{\circ}\right)$, completely anti-phase, by pointing left $\left(-180^{\circ}\right)$, a situation where the maximum in the A series leads the maximum in the B series with $90^{\circ}$, by pointing straight down $\left(-90^{\circ}\right)$ and when the maximum in the A series lags the maximum in the B series with $90^{\circ}$, by pointing straight up $\left(+90^{\circ}\right)$. For instance, when considering a climate variability at the time scale of 1 year, the annual scale, the phase difference of $-90^{\circ}$ means that A lags B by 3 months, while a phase difference of $+90^{\circ}$ means the opposite, i.e. that B lags A by 3 months.

Firstly, the wavelet coherence and phase differences between the monthly CL time series and each monthly climate index (LST, NDVI and PRP) as well as between the climate indices themselves for the 20022009 period were calculated. In these calculations, the different time series contain their corresponding seasonal cycles. The wavelet coherence and phase differences between the El Niño 3.4 SST index and the CL time series as well as El Niño 3.4 SST index and the PRP one were also calculated. For these calculations, the monthly departures of the CL and PRP indices from the monthly climate indicators of the 20022009 period were used.

\section{Results}

\section{Seasonal index changes}

Figure 1a-d show the monthly boxplots of the CL, LST, NDVI and PRP time series. All four variables show strong seasonal cycles.

\section{Cutaneous leishmaniasis}

The highest number of CL cases was seen in the November-April period with the largest median in February, while the lowest number of cases appeared from June to October with the smallest median in August (Figure 1a). The time interval of the six months between the largest and lowest medians indicates a symmetric seasonal cycle. The highest CL dispersion occurred in April, as indicated by the larger interquartile and the maximum value in this month, while the lowest happened in July as indicated by the smaller inter-quartile and the minimum value in this month. The outliers above the upper quartile from March to September indicate epidemic outbreaks (Figure 1a)

\section{Land surface temperature}

The LST boxplots show the highest values from August to November with the highest median in October, while the lowest LST values occurred in the period February-May with the lowest median in May (Figure 1b). The interval of seven months between the highest and the lowest median, compared to only five months between the lowest and the highest median, suggests an asymmetric seasonal cycle. Two outliers were noted, one lower than the lower quartile in April and another above the upper quartile in November. The highest LST dispersion occurred in October, while the lowest happened in August. The LST also had quite a small, annual amplitude due to the high incidence of solar radiation in the region analyzed.

\section{Normalized difference vegetation index}

Figure 1c displays the highest NDVI values from July to October and the largest median in the period July-August, while the lowest values were from February to May and the smallest median occurred in May.

\section{Monthly gridded precipitation}

The highest PRP values were seen from January to May with the largest median in May, while the lowest values appeared in the period July-November with the smallest median in September (Figure 1d). The highest dispersion occurred in December-January and the lowest in September. Also, the interval of eight months between the lowest and highest median vs. four months between the highest and the lowest suggests an asymmetric seasonal cycle.

\section{Associations between cutaneous leishmaniasis num- bers and climate variables}

Figure 2 depicts the coherence and phase differences between the CL numbers and the climatic indices. Because the time series contains the annual cycle, all these indices showed significant coherences at the annual scale (0.7-1.2 year) during the whole period of analysis. In addition, they also showed significant coherences at the 0.25-0.5-year time scale, but only for relatively short periods.

Figure 2a shows significant coherences between the NDVI and CL time series during the whole period at the biennial scale (1.5-2.5 years). At the annual scale (0.7-1.2 year), the phase differences between NDVI and CL varied from $-120^{\circ}$ to $-150^{\circ}$, which is consistent with the seasonal findings of these indices. In addition, at this scale, the NDVI had a lag period with respect to CL by 4 to 5 months. At the biennial scale, the phase differences of $-90^{\circ}$ imply that the NDVI lags CL by approximately 6 months.

The LST and CL series exhibited a significant coherence at the annual scale with a phase difference of $-120^{\circ}$ and also clear coherences with phase differences varying from $-90^{\circ}$ to $-120^{\circ}$ at the biennial time scale during the 2004-2007 period (Figure 2b). Thus, at the annual
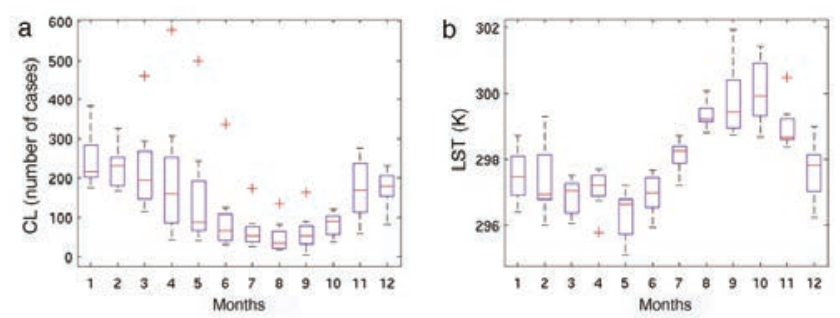

C

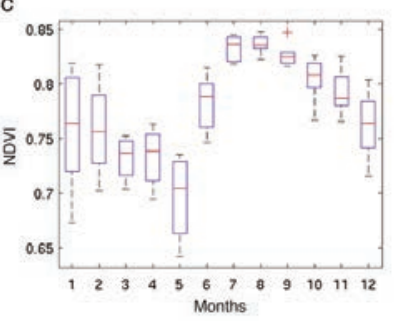

d

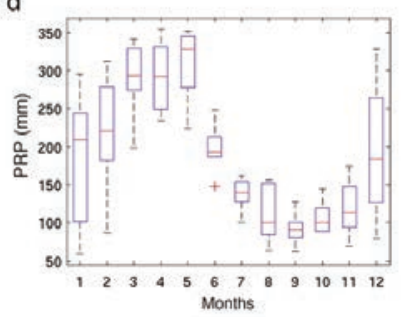

Figure 1. Monthly boxplots for the 2002-2009 period of: a) cutaneous leishmaniasis (CL); b) land surface temperature (LST); c) normalized difference vegetation index (NDVI); and d) monthly gridded precipitation (PRP). 
scale, for the phase difference of $-120^{\circ}$, LST lagged CL by 4 months.

For the PRP and the CL, significant coherences occur for the annual scale with phase differences varying from +45 to +90 degrees (Figure 2c). Therefore, regarding the annual scale, a maximum PRP precedes the minimum CL by 3 to 5 months, while a minimum PRP precedes the maximum CL by 3 to 5 months, which is in accordance with the seasonal behaviour of the PRP and CL indices.

As seen in Figure 3a, LST and NDVI time series showed significant coherences at the sub-annual scale after 2006 and at the annual scale during the whole period with phase differences varying from zero to $30^{\circ}$. Thus, at the annual scale, both warm surface conditions in the MMR together with high NDVI values occurred nearly simultaneously with cold conditions and low NDVI (less than 1 month difference), which is in agreement with the seasonal relations between the LST and the NDVI variables. The significant coherences observed at the 4-year scale (3.5-4.5 years), with the phase differences varying from $-45^{\circ}$ to $90^{\circ}$, imply that LST lagged NDVI by 0.5 to 1 year at this time scale.

The PRP and NDVI time series showed significant coherences before 2006 and during 2007 at the sub-annual scale, but the highest significant coherences occurred at the annual time scale with phase differences varying from $-120^{\circ}$ to $-150^{\circ}$ (Figure $3 \mathrm{~b}$ ). Therefore, at the annual scale, the PRP lagged NDVI by 4 to 5 months, confirming the seasonal relations between these variables. The noted significant coherences for the 4-year scale during the whole period of analysis with phase differences of approximately $180^{\circ}$ indicate that the PRP and NDVI were out of phase at this time scale.

The PRP and LST time series were out phase at the annual scale, as indicated by the highest significant coherences at this scale, with the phase differences of $180^{\circ}$ between these two variables (Figure 3c). Since significant coherences appeared also for the biennial and 4-year scales with a phase difference of $-135^{\circ}$. At the biannual scale, the PRP lagged LST by 9 months.

The El Niño 3.4 index and the monthly CL anomalies showed high significant coherences at the biennial scale during the whole period of analysis with phase differences of $-90^{\circ}$ (Figure $4 \mathrm{a}$ ). In this case, the El Niño 3.4 index lagged the CL anomalies by 6 months. Thus, when an El Niño event is established, above-normal numbers of CL cases occur 6 months later in the MMR, while La Niña events result in below-normal numbers of CL cases with the same lag period.

For the El Niño 3.4 time series and the monthly PRP anomalies, significant coherences occurred at the biennial and 4-year scales with phase differences of approximately $+135^{\circ}$ and $+90^{\circ}$, respectively (Figure 4b). If the first PRP maximum occurs in month 6 at the biennial scale, the first minimum follows by month 18 . In this case, for a phase difference of $135^{\circ}$, the first maximum for El Niño 3.4 would occur by month 15 . Therefore, for the biennial oscillation, El Niño precedes the dry conditions, and La Niña the wet conditions, in the MMR by 3 months. For the phase difference of $90^{\circ}$ at the 4 -year scale, El Niño precedes the dry conditions, and La Niña the wet conditions, by 12 months.

\section{Discussion}

The results presented here strongly suggest that the seasonal features of the climate and inter-annual climate variability affect the dynamics of the vector, thus causing variations in the number of CL cases in the MMR, a fact that should be useful for the design of control policies. The wavelet coherence and phase differences presented in this paper reveal that local environmental conditions play an important role on this seasonal cycle. At least, the maximum and the minimum
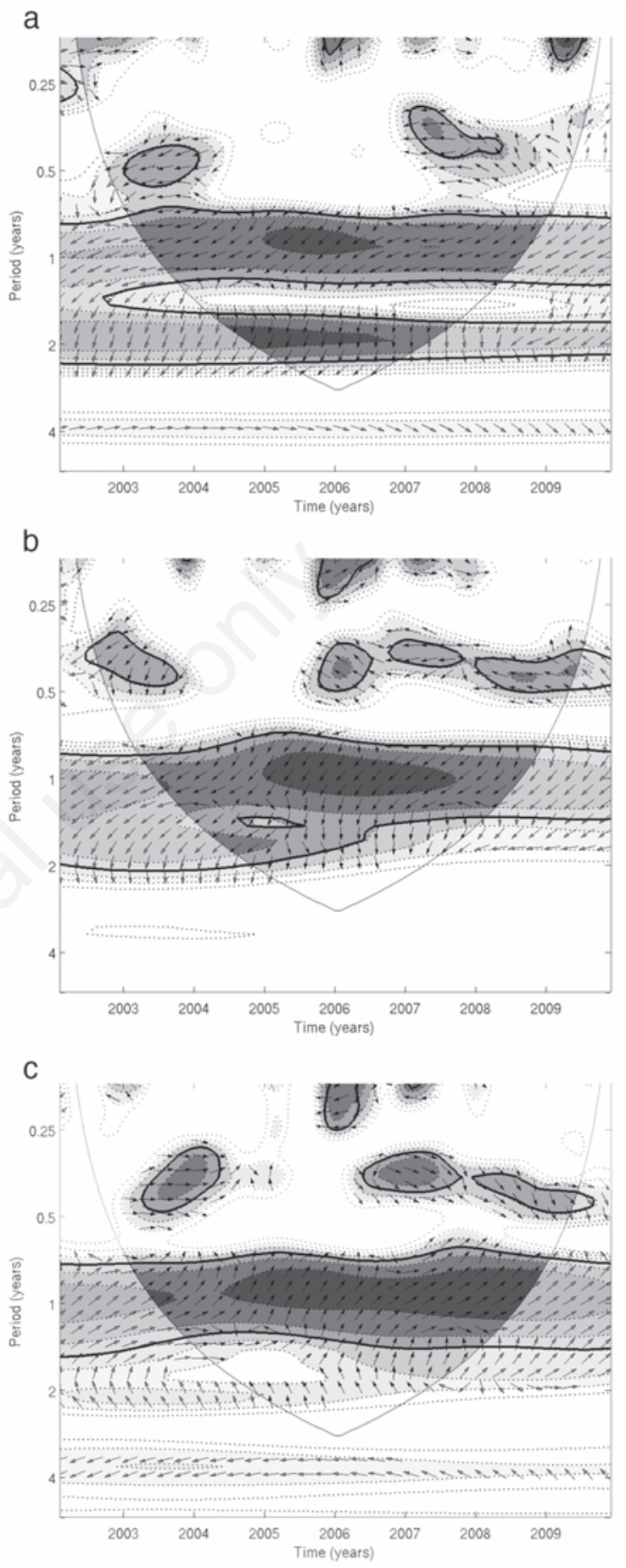

Figure 2. Squared wavelet coherence and phase differences between the time series indicated in each panel: a) normalized difference vegetation index and cutaneous leishmaniasis (CL); b) land surface temperature and $\mathrm{CL}$; and c) monthly gridded precipitation and $\mathrm{CL}$. The thick contour encompasses the significant coherences at the $95 \%$ confidence level assuming a red-noise spectrum. Dotted contours and shadings are for wavelet squared coherency and vary from 0.4 to 1.0 with intervals of 0.1 . The region where the edge effects are important is under the U-shape curve. Arrows are the phase differences with in-phase $\left(0^{\circ}\right)$, pointed to the right; antiphase $\left(180^{\circ}\right)$, pointed to the left; the first time series leading the second one by $90^{\circ}$, pointed downward; and the first time series lagging the second one by $90^{\circ}$, pointed upward. 
seasonal CL values seem to result from a sequence of local thermal and biological processes. At the annual scale, the phase differences (Figures 2 and 3) indicate that minimum PRP, maximum NDVI and maximum LST occur almost simultaneously and precede the maximum number of CL occurrences by 3 to 5 months, while maximum PRP, minimum NDVI and minimum LST instead precede the minimum number of CL occurrences, also by 3 to 5 months. Increased solar incidence during the dry season warms the environment leading to high LST values, which in turn favor high NDVI values. During the wet season, on the other hand, reduced solar incidence cools the land leading to low LST values, which favor low NDVI values. The thermal and vegetation conditions in the MMR during the dry season precede the maximum number of CL cases by 3 to 5 months, while they precede the minimum number of cases in the same timeframe in the wet season. This means that the maximum number of CL cases occurs at the beginning of or within the subsequent rainy season, while the minimum number of cases instead occurs in the dry season, indicating a close linkage between CL incidence and local climate conditions. The results strongly suggest that conditions favorable for the vector (dry and warm weather) in the longer perspective (the subsequent wet season) produce increased number of CL cases, while the opposite situation - wet and cold conditions - reduces eclosion, and thus also low vector density, leading to a minimum of CL incidence during the subsequent dry season.

The exploratory analyses of the climatic variables illustrate these seasonal cycles. For example, LST and PRP showed nearly synchronous and antisymmetric seasonal cycles. On the other hand, LST and NDVI seasonal cycles showed an approximate in-phase relation, with the cold period overlapping the period with the lowest NDVI values, and the warm period overlapping the period with the highest NDVI values. However, the seasonal relations among PRP, LST and NDVI were not exactly synchronous because the time intervals between the corresponding highest and lowest median were not the same. Whereas, the highest PRP median and the lowest medians for the LST and NDVI occurred in May, the highest NDVI median, the lowest PRP median and the highest LST median took place in the August-October period. Nevertheless, the relations of seasonal CL incidence and the climate parameter variations deserve a more careful analysis. The CL seasonal cycle follows approximately the seasonal rainfall variations in the MMR with the six months with the highest numbers of CL cases overlapping the rainy season, and the five months with the lowest numbers of CL cases overlapping the dry season (Figure 1a). However, the highest CL median in February occurred three months before the highest PRP median. In addition, the period with the highest LST and NDVI values preceded the onset month of the period with a high number of CL cases, while the period with the lowest LST and NDVI values preceded the onset month of the period with a low number of CL cases (Figure 1a-c). Furthermore, the highest medians of the NDVI and LST occurring in the August-October period preceded the largest CL median by 6 and 5 months. On the other hand, the highest PRP median, and the lowest medians for LST and NDVI in May preceded the lowest CL median by three months. So, the above analyses of the seasonal features of the CL, LST, NDVI and PRP do not allow to infer the causal relations between them.

The fact that the NDVI had the highest values from July to October, and the highest median in the July-August period, while displaying the lowest values from February to May and the lowest median in May (Figure 1c), is in agreement with Gurgel and Ferreira (2003), who found that the summer/winter mode of the NDVI annual cycle presents a maximum in September and a minimum in March in the Amazon region. Furthermore, the highest dispersion occurred in January, and
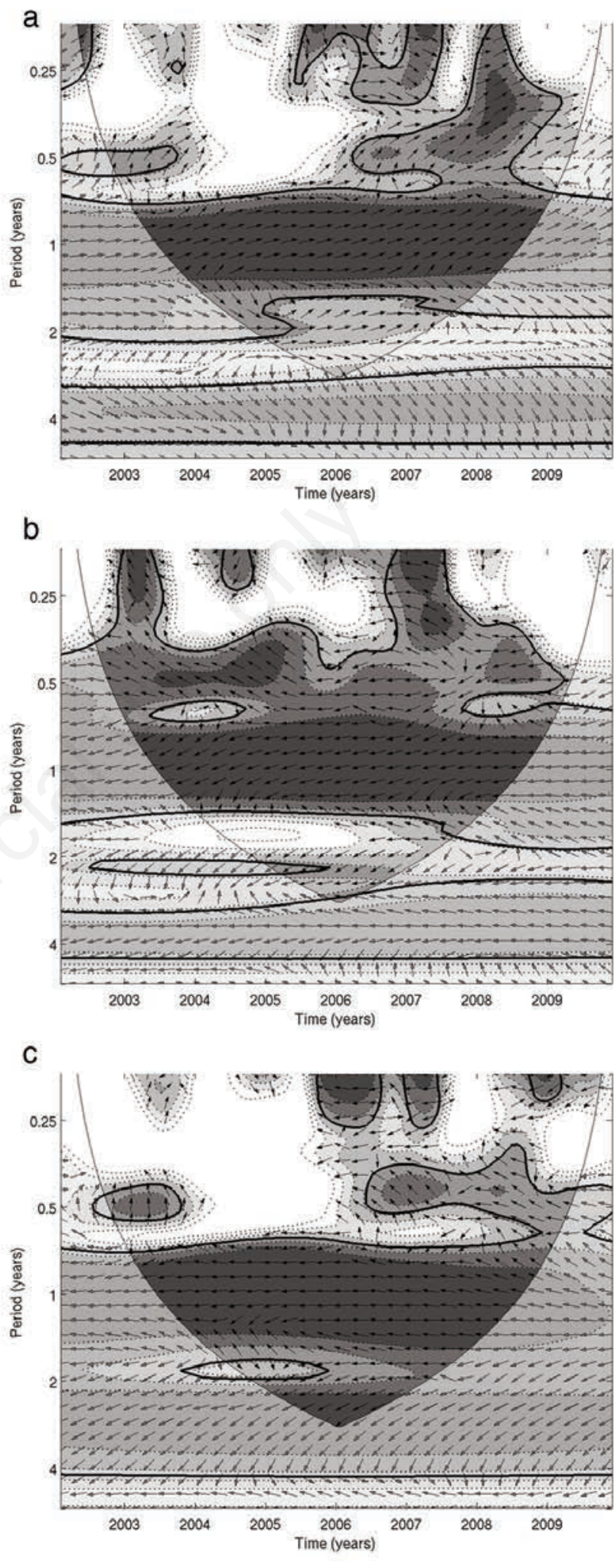

Figure 3. Squared wavelet coherence and phase differences between the time series indicated in each panel: a) land surface temperature (LST) and normalized difference vegetation index (NDVI); b) monthly gridded precipitation (PRP) and NDVI; and c) PRP and LST. Display is the same as in Figure 2. 
the lowest in September, when one outlier above the upper quartile was seen. Also, the interval of three months between the lowest and highest median, and the interval of nine months between the highest and the lowest medians, is indicative of an irregular seasonal cycle of the NDVI in the MMR area. The irregular NDVI seasonal cycle was also noted in the southern Amazon by Gurgel et al. (2003), who found the maximum NDVI values in June for this region and minimum values in two periods, one in February-March and the second, from September to November.

The results with respect to the associations between CL numbers and climate variables suggest that the local environmental conditions (NDVI, LST and PRP) control the succeeding number of CL cases through a sequence of processes as illustrated schematically in Figure 5 at the annual scale. The almost simultaneous occurrence of a minimum PRP, a maximum NDVI and a maximum LST precedes the maximum number of CL incidences by 3 to 5 months, while a maximum PRP, a minimum NDVI and a minimum LST precede the minimum number of CL cases by in the same timeframe. The high LST and NDVI values in the MMR during the dry season are early indicators (3 to 5 months ahead) of increased numbers of CL, while the low LST and NDVI values during the wet season indicates reduced number of CL cases with same time difference.

The analyses of CL association with El Niño 3.4 on the coherence and phase differences between local climate indices and the number of
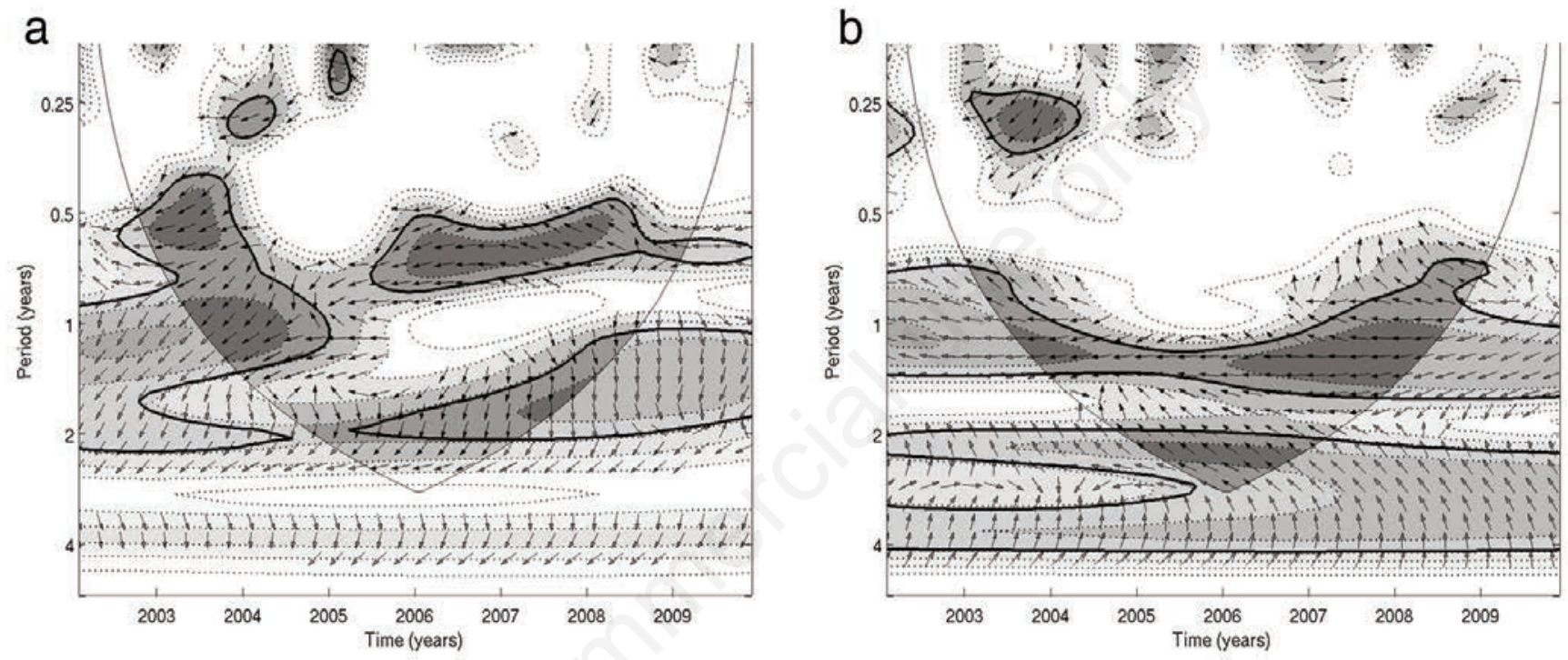

Figure 4. Squared wavelet coherence and phase differences between the time series indicated in each panel: a) El Niño 3.4 and cutaneous leishmaniasis anomalies; and b) Niño 3.4 and monthly gridded precipitation anomalies. Display is the same as in Figure 2.

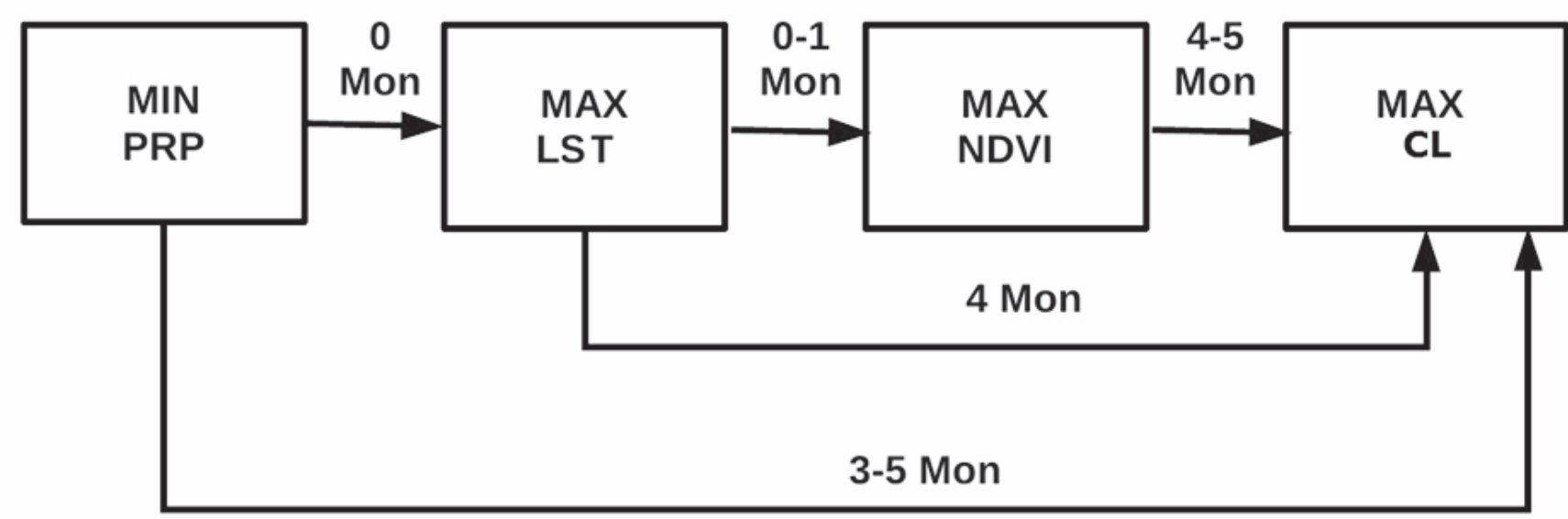

Figure 5. Relationship among monthly gridded precipitation, land surface temperature, normalized difference vegetation index and cutaneous leishmaniasis shown schematically for 1 -year time scale variations. 
CL cases show high coherence at the inter-annual time scale. At this scale, ENSO is the main phenomenon modulating the climate variability over the Amazon, mainly reflected by rainfall anomalies. An important result concerns the relationship between ENSO and the variation in the number of CL cases. Cardenas et al. (2006) documented an increase of these cases in north-eastern Colombia during El Niño and a reduction during La Niña, but the phase relation between ENSO and the number of CL cases were not discussed. Here, we examine the phase relation between the El Niño 3.4 and the number of CL cases, and we also provide a possible explanation for this relation based on environmental parameters. The strongest coherences between El Niño 3.4 and the CL and PRP appeared at the biennial time scale, which is intrinsic to ENSO (Rasmusson et al., 1990; Tourre and White, 2005, 2006). Rasmusson et al. (1990) showed that ENSO is phase-locked at this time scale with the mean annual cycle of the SST in the tropical eastern Pacific and that ENSO is not related to the equatorial stratospheric Quasi-Biennial Oscillation of the zonal winds. Thus, the significant coherences between El Niño 3.4 and the CL and PRP for the biennial time scale are interpreted here in terms of ENSO influence. At this time scale, the results show that El Niño occurrences precede abovenormal number of CL cases by approximately 6 months, while La Niña occurrences precede below-normal number of CL cases by the same time. This time lag suggests that once El Niño is established, the consequent anomalously dry condition over MMR triggers the sequence of processes described above for the annual cycle, while La Niña results in anomalously wet condition that triggers the sequence of processes described above for the annual cycle. Therefore, considering the biennial time scale, once El Niño is established, anomalously dry conditions occur in the MMR area 3 months later, while La Niña results in anomalously wet conditions after the same time. The anomalously dry conditions cause warm land surface and high NDVI that favors an increase in the number of CL cases, while the anomalously wet conditions cause cold land surface and low NDVI, which lead to decreased numbers of CL cases. These conditions occur about 3 to 5 months before the maximum or minimum number of cases. Therefore, the time lag between $\mathrm{El}$ Niño and the above-normal number of CL cases in the MMR is approximately 6 months, while there is a similar time lag between La Niña and the below-normal number of cases in the MMR.

\section{Conclusions}

It is worth recalling that the SST variability in the tropical Atlantic also plays an important role in modulating rainfall variability along the Amazon River. The tropical Atlantic variability is correlated with the Pacific ENSO variability, such that a warming in the tropical North Atlantic is observed four to five months after the mature stage of an El Niño (Enfield and Mayer, 1997). The anomalous warming in the tropical North Atlantic takes part in the inter-hemispheric anomalous gradient SST mode in the tropical Atlantic, which is one of the main SST variability mode in this oceanic sector. This mode has been claimed to be one of the main features of the decadal variability in the tropical Atlantic (e.g., Servain, 1991; Andreoli and Kayano, 2003). For this reason, an analysis using SST Atlantic indices should include a longer period of data than that available for the present study. Therefore, the analysis here does not involve indices representing the tropical Atlantic variability, but focused on the ENSO effects.

\section{References}

Andreoli RV, Kayano MT, 2003. Evolution of the equatorial and dipole modes of the sea surface temperature in the Tropical Atlantic at decadal scale. Meteor Atmos Phys 83:277-85.

Barbosa MGV, Fé NF, Marcião AHR, Silva APT, Monteiro WM, Guerra JA0, 2008. Fauna de Flebotomíneos (Diptera: Psychodidae) em um Foco de Leishmaniose Tegumentar Americana na área periurbana de Manaus, Estado do Amazonas. Rev Soc Bras Med Tro 41:485-91.

Bavia ME, Carneiro DD, Gurgel HC, Madureira Filho C, Barbosa MG, 2005. Remote sensing and geographic information systems and risk of American visceral leishmaniasis in Bahia, Brazil. Parasitologia 47:165-9.

Becker C, Grieser J, Rudolf B, 2005. A new monthly precipitation climatology for the global land areas for the period 1951 to 2000. Germany Weather Service, Offenbach, Germany.

Bounoua L, Kahime K, Houti L, Blakey T, Ebi KL, Zhang P, Imhoff ML, Thome KJ, Dudek C, Sahabi S A, Messouli M, Makhlouf B, Laamrani AE, Boumezzough A, 2013. Linking climate to incidence of zoonotic cutaneous Leishmaniasis (L. major) in Pre-Saharan North Africa. Int J Environ Res Public Health 10:3172-91.

Cabaniel SG, Rada TL, Blanco GJJ, Morales AJR, Escalera AJP, 2005. Impacto de los eventos de El Niño Southern Oscillation (ENSO) sobre la leishmaniosis cutánea en Sucre, Venezuela, a través del uso de información satelital, 1994 -2003. Rev Peruana de Med Exp Y Salud Púb 22:32-7.

Cardenas R, Sandoval CM, Rodríguez-Morales AJ, Paredes CF, 2006. Impact of climate variability in the occurrence of leishmaniasis in Northeastern Colombia. Am J Trop Med Hyg 75:273-7.

Cazelles B, Chavez M, Magny GC, Guégan JF, Hales S, 2007. Timedependent spectral analysis of epidemiological time-series with wavelets. J R Soc Interface 4:625-36.

Chaves LF, Pascual M, 2006. Climate cycles and forecasts of cutaneous Leishmaniasis, a nonstationary vector-borne disease. Plos Med 3:1320-7.

Delgado L, Córdova K, Rodriguez AJ, 2004. Epidemiological impact of climatic variation on malaria dynamics in a Northeastern Region of Venezuela. Int J Infect Dis 8:23-4.

Enfield DB, Mayer DA, 1997. Tropical Atlantic sea surface temperature variability and its relation to El Niño-Southern oscillation. J Geophys Res 102:929-45.

Gagnon AS, Smoyer-Tomic KE, Bush AB, 2002. The El Niño southern oscillation and malaria epidemics in South America. Int $\mathrm{J}$ Biometeorol 46:81-9.

Green RM, Hay SI, 2002. The potential of pathfinder AVHRR data for providing surrogate climatic variables across Africa and Europe for epidemiological applications. Remote Sens Environ 79:166-75.

Grinsted A, Moore JC, Jevrejeva S, 2004. Application of the cross wavelet transform and wavelet coherence to geophysical time series. Nonlinear Proc Geoph 11:561-6.

Guerra JA0, Barros MLB, Guerra MVF, Talhari S, Paes MG, 1998. Leishmaniose Tegumentar Americana (LTA) no município de Manaus. Aspectos epidemiológicos. Rev Soc Bras Med Tro 31:172.

Gurgel HC, Ferreira NJ, 2003. Annual and interannual variability of NDVI in Brazil and its connections with climate. Int J Remote Sens 24:3595-609.

Gurgel HC, Ferreira NJ, Luiz AJB, 2003. Estudo da variabilidade do NDVI sobre o Brasil utilizando-se a análise de agrupamentos. Rev Bras Eng Agrícola e Ambiental 7:85-90.

Kousky VE, Ropelewski CF, 1989. Extremes in the Southern oscillation 
and their relationship to precipitation anomalies with emphasis on the South American region. Rev Bras Meteorol 4:351-63.

Marengo J, 1992. Interannual variability of surface climate in the Amazon basin. Int J Climatol 12:853-63.

Passos VMA, Andrade AC, Silva ES, Figueiredo EM, Falcão AL, 1984. Inquérito canino em foco recente de leishmaniose tegumentar no município de Sabará, Região Metropolitana de Belo Horizonte. Rev Soc Bras Med Tro 29:323-9.

Patz JA, McGeehin MA, Bernard SM, Ebi KL, Epstein PR, Grambsch A, Gubler DJ, Reither P, Romieu I, Rose JB, Samet JM, Trtanj J, 2000. The potential health impacts of climate variability and change for the United States: executive summary of the report of the health sector of the U.S. National assessment. Environ Health Persp 108:367-76.

Pessoa SB, Barreto MP, 1948. Leishmaniose Tegumentar Americana. Ministério da Educação e Saúde Serviço de Documentação, Rio de Janeiro, Brazil.

Philander SGH, 1990. El Niño, La Niña, and the Southern oscillation. Academic Press, Waltham, MA, USA.

Rasmusson EM, Wang X, Ropelwski CF, 1990. The biennial component of ENSO variability. J Marine Syst 1:71-96.

Ropelewski CH, Halpert S, 1987. Global and regional scale precipitation patterns associated with the El Niño/Southern oscillation. Mon Weather Rev 115:1606-26.

Rudolf B, Rubel F, 2005. Global precipitation. In: Hantel M, ed. Observed global climate, new series on landolt-bornstein: numerical data and functional relationships in science and technology. Springer, Berlin, Germany, pp 11.1-11.24.

Schneider U, Becker A, Finger P, Meyer-Christoffer A, Ziese M, Rudolf B, 2013. GPCC's new land surface precipitation climatology based on quality-controlled in situ data and its role in quantifying the global water cycle. Theor Appl Climatol 115:15-40.

Servain J, 1991. Simple climatic indices for the Tropical Atlantic Ocean and some applications. J Geophys Res 96:15137-46.

Torrence C, Webster P, 1999. Interdecadal changes in the ENSO-monsoon system. Available from: http://journals.ametsoc.org/ doi/abs/10.1175/1520-0442\%281999\%29012\%3C2679\%3 AICITEM\%3E2.0.C0\%3B2

Tourre YM, White WB, 2005. Evolution of the ENSO signal over the tropical Pacific-Atlantic domain. Geophys Res Lett 32:L07605.

Tourre YM, White WB, 2006. Global climate signals and equatorial SST variability in the Indian, Pacific and Atlantic oceans during the 20th century. Geophys Res Lett 33:L06716.

Tourre YM, Jarlan L, Lacaux J-P, Rotela CH, Lafaye M, 2008. Spatio-temporal variability of NDVI-precipitation over southernmost South America: possible linkages between climate signals and epidemics. Environ Res Lett 3:1-9.

Wilks DS, 2006. Statistical methods in the atmospheric sciences. Academic Press, Waltham, MA, USA.

Werneck GL, Maguire JH, 2002. Modelagem espacial utilizando modelos mistos: um estudo ecológico sobre leishmaniose visceral em Teresina, Piauí, Brasil. Cad Saude Publica 18:633-7. 